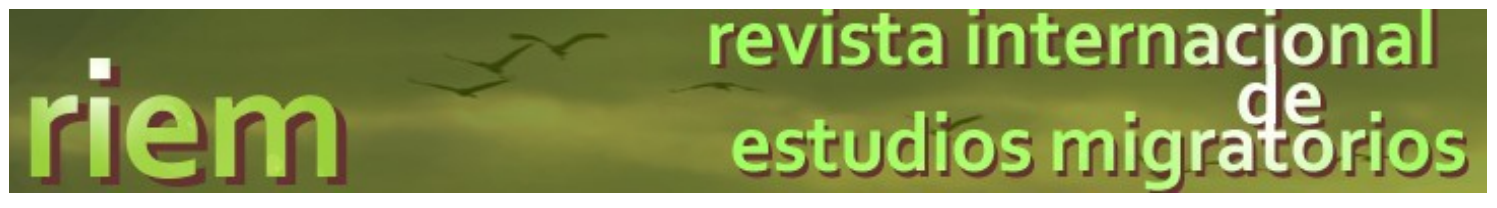

\title{
Enfermeras españolas en el extranjero: Estudio comparativo de Reino Unido y España
}

Spanish nurses abroad: a comparative study of the United Kingdom and Spain

\author{
de Miguel Jesús Rodríguez Arrastia (2017) \\ Universidad de Almería: Tesis Doctoral ${ }^{1}$
}

Recensión por

Miguel Jesús Rodríguez Arrastia

Profesor Interino de Enfermería, Universidad de Almería, Almería, España

Correspondencia: Miguel Jesús Rodríguez Arrastia. Universidad de Almería. La Cañada de San Urbano s/n, Aulario C (263), Almería. España. Email: mra887@ual.es

(C) Revista Internacional de Estudios Migratorios. CEMyRI. UAL (España)

\footnotetext{
${ }^{1}$ Directora: Dra. Carmen González Canalejo; Defendida en la Universidad de Almería el 09/06/2017; Calificación de Sobresaliente "Cum laude"; Mención internacional.
} 
La emigración de miles de enfermeras y enfermeros españoles hacia Reino Unido y la experiencia propia han sido los principales desencadenantes que han llevado a la elaboración de esta tesis doctoral en la que abordamos el fenómeno que ha impulsado a más de 7.948 titulados en enfermería, a abandonar las posibilidades de desarrollo profesional en España, entre el año 2007 a 2016. Para contestar al problema que se investiga sobre las causas que han impulsado a este grupo profesional a cambiar sus expectativas de vida, nos hemos tenido que servir de la complejidad que ello conlleva en el terreno de los cambios culturales, laborales y sociales, de recursos conceptuales y herramientas metodológicas que nos ayuden a explicar este contexto. Se trata de una investigación amplia, que aborda el estudio comparativo de ambos países: Reino Unido-España sobre la profesión enfermera y el fenómeno migratorio de este colectivo.

Distribuido a lo largo de cuatro capítulos, el principal objetivo ha sido el identificar las causas que han impulsado a un número tan importante de enfermeras/os españolas/es a elegir Reino Unido como destino laboral. Para intentar acercarnos a este proceso se marcó como prioridad profundizar en los detonantes de la emigración, como ha sido la crisis económica vivida en España durante el periodo señalado, previo análisis comparativo del desarrollo de la práctica enfermera en ambos países. Finalmente, dados los cambios socio-políticos de última hora en Reino Unido, se ha hecho imprescindible incluir un análisis pormenorizado que reflejara el impacto del Brexit en las expectativas de futuro del grupo profesional emigrado.

El método usado para este trabajo de corte cualitativo responde a un diseño fenomenológico que ha permitido reconstruir las experiencias profesionales e historias de vida a través de la voz de las emigradas. Las fuentes utilizadas para el marco de referencia y la contrastación de datos han sido amplias. Además de la bibliografía secundaria, se ha combinado un volcado hemerográfico, que recoge los registros de 9.559 números de periódicos analizados, con más 371 entrevistas realizadas a enfermeras y enfermeros repartidos por toda la geografía de Reino Unido. Ello asegura una muestra representativa que confiere un grado de fiabilidad mayor del $90 \%$ en los resultados analizados obtenidos.

Invitando a sumergirse en los resultados y enlazándolos a lo que ha ido apareciendo en los medios de comunicación, estas historias cobran mayor importancia, si cabe, en un escenario donde la enfermería emigrada tiene tanta representación. Respondiendo al carácter feminizado de la profesión enfermera, la mayoría del grupo de estudio está formado por mujeres jóvenes, donde un $20 \%$ eran recién tituladas en el momento de la emigración. Se fueron de España por falta de trabajo y mala calidad en las contrataciones ofrecidas por las instituciones sanitarias. La estela de la crisis 
económica ha ido paralela a la emigración del grupo profesional, cuya curva desciende a partir de enero de 2016, coincidiendo con el anuncio de la salida de la Unión Europea por parte de Reino Unido.

Como conclusiones cabe resaltar que esta última fecha, que coincide con el inicio del Brexit, marca un descenso del número de enfermeras españolas en Reino Unido, pero ello no implica su regreso a España. Muchas/os de estos profesionales, que han ganado en el dominio de la lengua inglesa y han enriquecido su experiencia profesional, piensan en volver a emigrar a otros países, mientras no mejoren las condiciones de vida en España. Como motivo de permanencia destaca el reconocimiento profesional de las enfermeras españolas en el país de acogida, dada la contrastada calidad de la enfermería española a nivel internacional. La incertidumbre que representa la aplicación del artículo 50 a la hora de invalidar los convenios entre países europeos es una incógnita que aún no se puede resolver. De momento, desde enero de 2016 a enero de 2017, casi mil de las que emigraron están revirtiendo el inicio migratorio de hace años. 